\title{
SHORT REPORT \\ Giardia outbreak associated with a roadside spring in Rensselaer County, New York
}

\author{
B. A. BEDARD ${ }^{1 *}$, R. ELDER ${ }^{2}$, L. PHILLIPS ${ }^{2}$ AND M. F. WACHUNAS ${ }^{2}$ \\ ${ }^{1}$ Genesee and Orleans County Health Department, Albion, NY, USA \\ ${ }^{2}$ Rensselaer County Health Department, Troy, NY, USA
}

Received 21 March 2016; Final revision 13 June 2016; Accepted 14 June 2016; first published online 8 July 2016

\section{SUMMARY}

In September 2009, the Rensselaer County Department of Health investigated an increase in Giardia duodenalis cases. The epidemiological investigation identified that a source of the illness could be a roadside spring located in the eastern part of the county. Epidemiological and environmental health staff conducted a site visit to the roadside spring and found several concerns. Water samples were collected from the roadside spring and sent to the New York State Department of Health for analysis. The water sample results indicated the presence of empty Giardia cysts. Prevention methods occurred and the roadside spring was destroyed. A total of 36 laboratory-confirmed cases of Giardia were identified from this outbreak that included residents of New York State and Massachusetts.

Key words: Giardia, outbreaks, public health.

In the United States, Giardia duodenalis is the most common enteric parasitic protozoan infection [1]. The transmission occurs by the faecal-oral route by the ingestion of the Giardia cysts from an infected person's faeces or by ingesting the parasite from contaminated food or water [1-3]. Giardia infection symptoms vary from someone being asymptomatic to an acute gastrointestinal illness (diarrhoea, abdominal cramps, malabsorption, weakness, weight loss) [3, 4]. The incubation period for Giardia is from 3-25 days [3]. Humans, wild and domesticated animals are the reservoir for this infection [3-6].

Giardia is a reportable disease that all local health departments in New York State (NYS) are mandated to investigate under NYS sanitary code. Once these

\footnotetext{
* Author for correspondence: B. A. Bedard, MPH, Genesee and Orleans County Health Departments, 14012 Route 31 West, Albion, NY 14411, USA.

(Email:Brenden.Bedard@co.genesee.ny.us)
}

suspected cases are identified they are contacted and interviewed with a standard New York State Department of Health (NYSDOH) Giardia questionnaire (for questionnaire see Supplementary material) that identifies a series of exposure questions. The questionnaire asks about symptoms, food and water exposure, primary source of drinking water, travel history, animal exposure and contacts with similar symptoms. The answers to the standard questionnaire are then entered via a computer into the NYSDOH Communicable Disease Electronic Surveillance System (CDESS).

In September 2009, an increase of Giardia cases was observed in Rensselaer County. Rensselaer County has a population of about 160000 and is located on the eastern side of the Hudson River in NYS and the county has an eastern border with the states of Vermont and Massachusetts. Epidemiological staff from Rensselaer County Department of Health $(\mathrm{RCDOH})$ interviewed these cases with a NYSDOH 


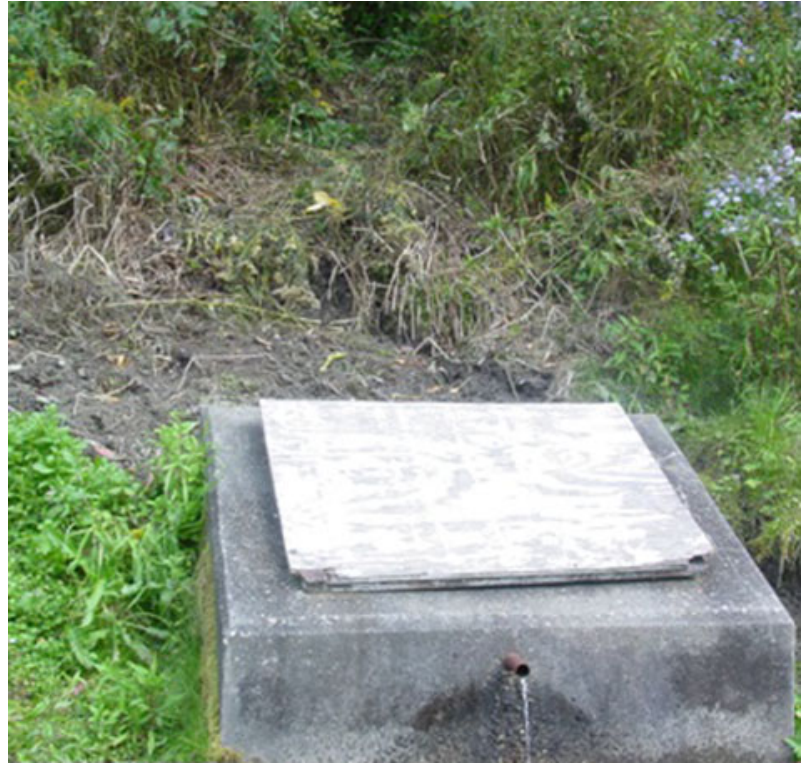

Fig. 1. Roadside spring box on 17 September 2009, located on Route 22 in the town of Stephentown, Rensselaer County, New York.

standard Giardia hypothesis-generating questionnaire. On 16 September 2009, a cluster of four Giardia cases were reported. During the personal interviews of these four ill cases, a potential source of their illness was identified. The four cases identified consumed water during the incubation period from a local roadside spring which was located in the town of Stephentown close to the Massachusetts border.

On 17 September 2009, a field visit to the location of the roadside spring was conducted by $\mathrm{RCDOH}$ environmental and epidemiological staff. The site visit identified concerns regarding this spring. The spring box was a concrete box with a removable piece of wood on top and had a 1-inch pipe sticking out of the concrete box from which water continually flowed (Fig. 1). Just above the spring box the health department staff noticed significant ground disturbance of unknown origin. Based on the site visit, water samples were collected and submitted to the NYSDOH Wadsworth Laboratory for analysis. NYSDOH regional epidemiologists were notified of the potential source of illness and were requested to conduct regional Giardia surveillance and contact Massachusetts and Vermont health departments. The property owner of the roadside spring was notified and was told that the spring was suspected to be causing illness. The owner placed temporary fencing around the spring box and posted a sign indicating to not drink the water.
The following day, $\mathrm{RCDOH}$ issued a press release warning people not to drink water from this roadside spring and if they had any water from the spring to discard it immediately. The press release indicated that the spring was under investigation for Giardia illness and if anyone who drank from the spring were symptomatic with symptoms consistent with Giardia to contact their doctor and get tested. On 22 September 2009, additional cases of illness were reported to $\mathrm{RCDOH}$ and there was evidence that people were not heeding the warnings at the roadside spring and still collecting water. The RCDOH contacted the owner of the spring again with these new findings and the owner demolished the spring box (Fig. 2). Water samples collected from the spring came back positive for Escherichia coli bacteria and the presence of empty Giardia cysts. The water sample results indicated faecal contamination of the roadside spring. On 24 September 2009, $\mathrm{RCDOH}$ issued a second press release informing the public of the presence of the Giardia parasite and urged residents if they still had water from the spring to discard it immediately and consult their doctor if they developed any symptoms.

A total of 36 laboratory-confirmed cases of Giardia were identified from four New York counties (Albany, Rensselaer, Schenectady, Suffolk) and the state of Massachusetts. Drinking water from this roadside spring was the only common variable among all of the laboratory-confirmed cases. The illness onset dates were from 9 August to 1 October 2009. The median age of patients was 52 years (range 9-76 years); $57 \%$ of the cases were female. Symptoms identified by the 36 cases included diarrhoea (92\%), nausea (64\%), abdominal cramps $(72 \%)$, bloating or gas (61\%), weight loss $(53 \%)$ and fever $(5 \%)$.

The NYSDOH Wadsworth laboratory used the 'United States Environmental Protection Agency Method 1623: Cryptosporidium and Giardia in Water by Filtration, Immunomagnetic Separation, and Immunofluorescence Assay Microscopy' to detect the empty Giardia cysts. Molecular analysis was not done on the environmental and human isolates to determine genotyping of $G$. duodenalis. The method used for the detection of total coliforms and E. coli was Colilert ${ }^{\mathbb{B}}$ in a Quanti-Tray ${ }^{\circledR}$ format (IDEXX Laboratories Inc., USA) according to the manufacturer's instructions.

To the best of our knowledge, this is the first reported Giardia outbreak associated with drinking from a roadside spring in the literature. After the Giardia outbreak was over the $\mathrm{RCDOH}$ conducted 


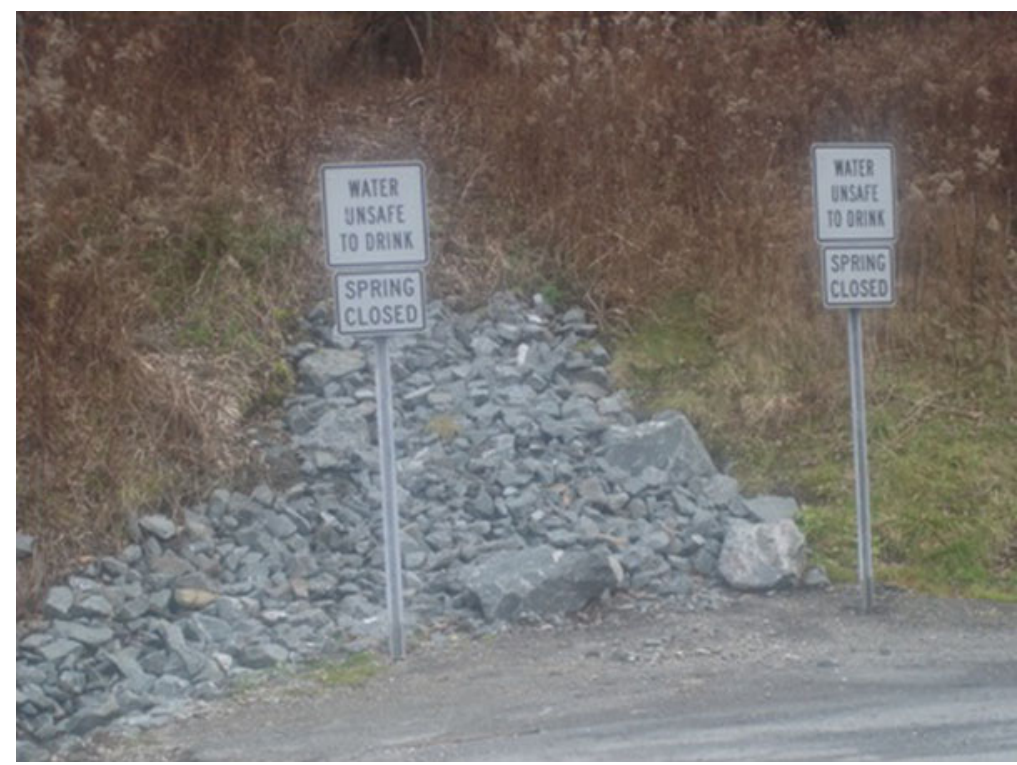

Fig. 2. Roadside spring box demolished, located on Route 22 in the town of Stephentown, Rensselaer County, New York.

surveillance for other roadside springs located in the county. This surveillance identified two additional roadside springs. The $\mathrm{RCDOH}$ contacted the property owners of these two springs and encouraged them to place signage to indicate that drinking the water was at the individual's own risk. Based on this recommendation one of the property owners voluntarily destroyed their roadside spring and the owner of the second spring installed permanent warning signs. Water testing was not done at these additional roadside springs.

Local health departments follow the NYSDOH Sanitary Code for water testing. The roadside spring was not considered an approved source of drinking water since the source had not been evaluated and found to be of satisfactory sanitary quality. Interviews from those infected indicated that the cases regularly consumed water from this roadside spring in Stephentown and some indicated that this was their routine source of drinking water. Swistock et al., stated that $10 \%$ of the rural Pennsylvania population indicated that a roadside spring was a routine source of drinking water [7].

The people who drank from the roadside spring in Stephentown probably thought that this was a healthier choice for drinking water since it was perceived as being from a pure natural spring. Education can be given by local health departments to their communities about not drinking water from unregulated roadside springs due to the risk of illness. Local health departments should also conduct surveillance to see if they have any roadside springs in their jurisdiction and actively inform the landowners of the risk associated with having an unregulated water source that the public consumes. By conducting this surveillance and educating the public this could reduce future outbreaks of illness. When the roadside spring in Stephentown was removed it ended the Giardia outbreak and prevented any future disease.

\section{SUPPLEMENTARY MATERIAL}

For supplementary material accompanying this paper visit http://dx.doi.org/10.1017/S0950268816001497.

\section{ACKNOWLEDGEMENTS}

We thank the NYSDOH Center for Environmental Health, Capital Area Environmental Health and the Wadsworth Center for environmental and laboratory support. We also thank Peter Drapkin, Dennis Croswell, Timothy Vickerson and Ellen BraunHowland from the NYSDOH.

\section{DECLARATION OF INTEREST}

None.

\section{REFERENCES}

1. Centers for Disease Control and Prevention. Giardiasis surveillance United States, 2011-2012. Morbidity and Mortality Weekly Report 2015; 64: 15-25. 
2. Center for Disease Control and Prevention. (http://www.cdc. gov/parasites/giardia/pathogen.html). Accessed4 March 2016.

3. Heymann DL. Control of Communicable Diseases Manual, 20th edn. Washington, DC: American Public Health Association, 2015, pp. 234-236.

4. Rafiei A, et al. Investigation of possible correlation between Giardia duodenalis genotypes and clinical symptoms in Southwest of Iran, Iran. Iranian Journal of Parasitology 2013; 8: 389-395.

5. Torres-Chable OM, et al. Prevalence of gastrointestinal parasites in domestic dogs in Tabasco, southeastern
Mexico. Brazilian Journal of Veterinary Parasitology 2015; 24: 432-437.

6. Prystajecky $\mathbf{N}$, et al. Giardia spp. are commonly found in mixed assemblages in surface water, as revealed by molecular and whole-genome characterization. Applied and Environmental Microbiology 2015; 81: 4827-4834.

7. Swistock B, et al. Issues associated with the use of untreated roadside springs as a source of drinking water. Journal of Contemporary Water Research and Education 2015; 156: 78-85. 